\title{
AÇÃO SINDICAL NA ARGENTINA E NO BRASIL: UMA ANÁLISE A PARTIR DOS CASOS DA CUT E DA CGT NO ALVORECER DO SÉCULO XXI
}

\author{
UNION ACTION IN ARGENTINA AND BRAZIL: AN ANALYSIS FROM THE CGT AND \\ CUT CASE STUDIES IN THE DAWN OF THE 21ST CENTURY
}

\author{
Ana Paula Colombi ${ }^{1}$ \\ Lucila D'Urso ${ }^{2}$
}

\begin{abstract}
RESUMO
Neste artigo, tem-se como objetivo investigar em que medida a atuação da CUT e da CGT alterou a agenda do trabalho dos governos petistas e kirchneristas entre 2003 e 2014 e, ainda, indagar se suas práticas, seus discursos e seus resultados podem ser interpretados como um processo de revitalização ou recuperação sindical no Brasil e na Argentina. Em primeiro lugar, analisam-se as transformações no mercado e nas relações de trabalho. Num segundo momento, mapeiam-se as ações das centrais frente aos principais embates em torno dos aspectos centrais da relação de emprego. A pesquisa mostra que as reivindicações da CUT e da CGT se concentram majoritariamente no campo econômico, sem lograr maiores mudanças nos elementos que versam sobre as condições de trabalho, suas modalidades de contratação e a jornada laboral. Ambas as centrais privilegiaram uma atuação no âmbito institucional, o que limitou a capacidade de o movimento sindical reverter o processo de flexibilização das relações laborais, permitindo problematizar a tese da revitalização sindical nesses países.
\end{abstract}

Palavras-chave: Movimento sindical. Brasil. Argentina.

\section{ABSTRACT}

This article aims to identify in what measures the actions taken by the main trade union confederations of Brazil and Argentina (CUT and CGT) altered the labor agenda of their governments between 2003 and 2014 and to investigate the meaning of their practices in terms of a process of trade union recovery in these countries. The first section analyses the changes in the market and in labor relations, while its second section maps the confederations' actions before the major clashes around employment relationship aspects. The conclusion argues that CUT and CGT have prioritized claims in the economic field, without achieving greater changes in the elements that deal with working conditions, their contracting modalities and working hours. They did so by giving preference to an institutional role and compromising the capacity of the trade union movement to reverse the process of flexibilization of labor relations, which undermine the thesis of trade union recovery in these countries.

Keywords: Trade union movement. Brazil. Argentina.

\section{INTRODUÇÃO}

A chegada ao poder executivo do Partido dos Trabalhadores (PT) no Brasil e da Frente para la Victoria (FPV) na Argentina configurou um novo contexto para a ação coletiva nesses países. A melhora nos indicadores econômicos e sociais a partir de 2003 significou uma oportunidade histórica de fortalecimento do movimento sindical. Entretanto, a proximidade política e ideológica desses partidos com as principais centrais sindicais - Central Única dos Trabalhadores/CUT e Confederación General del Trabajo/CGT, respectivamente - trouxe

\footnotetext{
1 Ana Paula Colombi é doutora em Desenvolvimento Econômico pela Universidade Estadual de Campinas (UNICAMP), IE/ e pesquisadora do Centro de Estudos Sindicais e de Economia do Trabalho (CESIT/UNICAMP). Email: anafcolombi@gmail.com.

${ }^{2}$ Lucila D’Urso é doutora em Ciências Sociais pela Facultad de Ciencias Sociales, Universidad de Buenos Aires (UBA), onde também é professora de Sociologia do Trabalho. Possui bolsa de pós-doutorado pelo Consejo Nacional de Investigaciones Científicas y Tecnológicas (CONICET). Email: lucilafdurso@gmail.com.
} 
também o seguinte paradoxo: às centrais estava colocado o desafio de constituírem-se enquanto sujeitos políticos com capacidade para mobilizar suas reivindicações históricas ao mesmo tempo em que conformavam uma parcela nuclear da base de sustentação dos governos eleitos.

Decorrido mais de dez anos, alguns autores visualizaram um processo de recuperação da atividade sindical no Brasil (BOITO e MARCELINO, 2010) e de revitalização do movimento na Argentina (SENÉN GONZÁLEZ e DEL BONO, 2013). No primeiro caso, a recuperação estaria evidenciada na manutenção da ação grevista em nível razoavelmente alto, no caráter ofensivo das greves, nas conquistas salariais acima da inflação e no acirramento das disputas na cúpula do movimento sindical. Esses elementos também se encontram presentes no caso argentino, em que se destaca que o ressurgimento do sindicalismo peronista tradicional da CGT estaria baseado em um novo padrão de negociação ao nível das cúpulas, intitulado neocorporativismo segmentado, segundo o qual os sindicatos monopolistas, as associações empresariais e o governo concordavam com um salário mínimo geral e consistente com as metas de inflação (ETCHEMENDY e COLLIER, 2008).

Ambos os argumentos são baseados na recuperação da capacidade de as centrais sindicais negociarem ganhos econômicos para a classe trabalhadora. Entretanto, o movimento sindical, tanto no Brasil quanto na Argentina, nunca fora um sindicalismo unicamente de resultados, mas portador de uma identidade, no sentido proposto por Hyman (2001), baseada em uma longa história de organização da classe trabalhadora e de luta política em torno dos direitos dos trabalhadores (RODRIGUES, 2011; JAMES, 2013; BASUALDO, 2010). Por possuírem essa identidade específica é que esse processo de recuperação/revitalização da atividade sindical não se revela apenas na dimensão econômica da luta coletiva. Adentrando neste debate, este artigo traz uma análise das ações realizadas pelas principais centrais sindicais do Brasil e da Argentina (CUT e CGT) entre os anos 2003 e 2014. O objetivo é investigar em que medida as centrais alteraram a agenda do trabalho dos governos, para além das questões econômicas, e indagar se os resultados da ação podem ser interpretados como um processo de revitalização ou recuperação da ação sindical nesses países.

A pesquisa mostra que, com suas nuances, CUT e CGT exerceram um papel político profundamente condicionado à ligação estabelecida com os governos. Neste sentido, as reivindicações das centrais foram majoritariamente de corte econômico, sem lograr maiores mudanças nos elementos que versavam sobre a jornada de trabalho e as modalidades de contratação. Ambas as centrais privilegiaram uma atuação no âmbito institucional, o que limitou a capacidade de o movimento sindical reverter o processo de flexibilização das relações laborais. No caso brasileiro, aos ganhos econômicos expressivos se adicionaram poucos avanços no âmbito da legislação laboral. No caso argentino, a valorização dos salários veio acompanhada por uma série de medidas no campo das relações de trabalho. Nos dois países, entretanto, mesmo em um cenário de crescimento econômico e fortalecimento político-institucional, as mudanças na legislação trabalhista não lograram reverter o processo de flexibilização das relações de trabalho. Em seu conjunto, esses elementos permitem problematizar a existência de um processo de recuperação/revitalização da atuação das principais centrais sindicais no Brasil e na Argentina. Um processo desse tipo exigiria:

movimentos apreciáveis para a recuperação dos sindicatos como atores econômicos nacionais, sociais e políticos, uma recuperação significativa do poder e estratégias que promovam esses objetivos. Desenvolvimentos de pequena escala, não articulados com tais índices ou com os constrangimentos do contexto nacional constituem evidência do processo de revitalização, real ou potencial, somente se negligenciarmos um 
sentido necessário de escala e significado ${ }^{3}$ (MCILROY, 2008, p. 301, tradução nossa).

Para cumprir o objetivo proposto na primeira etapa deste artigo, são analisadas as transformações no mercado e nas relações de trabalho entre os anos 2003 e 2014. Essa etapa do estudo recorreu a bases nacionais oficiais, tais como a Pesquisa Nacional por Amostra de Domicílio (PNAD) e a Relação Anual de Informações Sociais (RAIS) para o caso brasileiro e, para o caso argentino, a Encuesta Permanente de Hogares (EPH) do Instituto Nacional de Estadística y Censos (INDEC) e relatórios da Subsecretaría de Programación Técnica y Estudios Laborales (SSPTyEL) do Ministerio de Trabajo Empleo y Seguridad Social (MTEySS). As bases de dados da Comissão Econômica para a América Latina e o Caribe (CEPAL) também foram utilizadas. Além disso, foi realizado um balanço da legislação laboral no período com base em fontes primárias e secundárias, com o intuito de perceber a manutenção da tendência de flexibilização laboral em ambos os países.

$\mathrm{Na}$ segunda etapa, mapeiam-se as formulações e ações da CUT e da CGT a fim de analisar como essas centrais sindicais se posicionaram frente às alterações e aos embates em relação aos principais aspectos da relação de emprego: remuneração, jornada de trabalho e formas de contratação.

\section{BRASIL E ARGENTINA: CRESCIMENTO ECONÔMICO, GERAÇÃO DE EMPREGO MANUTENÇÃO DA TENDÊNCIA DE FLEXIBILIZAÇÃO DAS RELAÇÕES LABORAIS}

Nos anos 2000, o maior crescimento econômico e a melhora nos indicadores do emprego foram fenômenos comuns em países como Brasil e Argentina, em um momento de ascensão do PT e da FPV ao Poder Executivo. Outro fenômeno comum, embora em diferentes proporções, foi a dificuldade para reverter a tendência de flexibilização das relações laborais que se apresentou na presente década.

Recém-saídos de crises cambiais e de uma década de baixo crescimento e deterioração do mercado de trabalho, esses países passaram a gozar de um ambiente internacional favorável e a adotar políticas públicas específicas para o aproveitamento do momento. Neste sentido, diversas pesquisas indicam que a mudança de direção da intervenção estatal em matéria de política econômica, social e laboral foi essencial para a recuperação do crescimento econômico e do mercado de trabalho em ambos os países (BARBOSA e SOUZA, 2010; BALTAR et al., 2010; NOVICK, MAZORRA e SCHLESER, 2008; PANIGO e NEFFA, 2009). Apesar das diferenças no que tange à natureza do crescimento econômico entre os anos 2003-2014, é possível visualizar (Gráficos 1 e 2) ciclos comuns de crescimento da economia e do emprego.

Os ciclos de crescimento e geração de emprego conformam movimentos similares em ambos os países. Entretanto, as causas do crescimento econômico por vezes se distanciam, e os efeitos sobre a dinâmica do mercado de trabalho adquirem movimentos singulares.

\footnotetext{
3 "Meaningfully, renewal/revitalization requires appreciable movement towards the recovery of unions as national economic, social and political actors, significant recuperation of power, and strategies which further these objectives. Small-scale developments, unarticulated with such indices or with a national context which constrains progress, constitute evidence of revitalization, actual or potential, only if we neglect a necessary sense of scale and significance".
} 
Gráfico 1: Crescimento do PIB (\% a.a) entre 2003-2014, Brasil e Argentina.

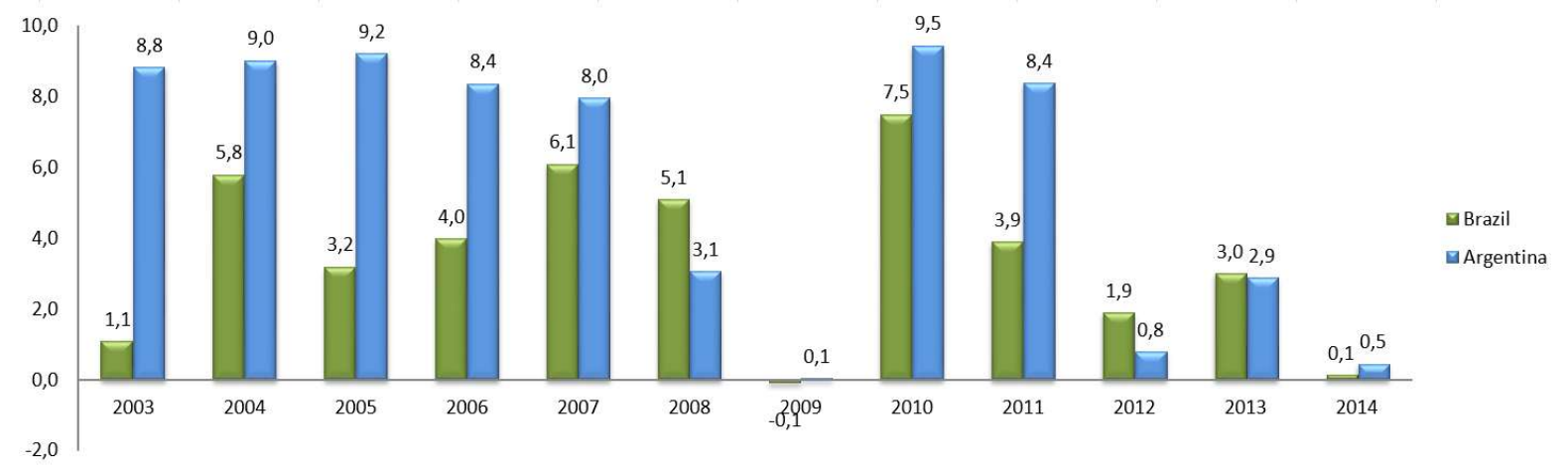

Fonte: CEPAL.

Gráfico 2: Taxa de desemprego (\% a.a) entre 2003-2014, Brasil e Argentina.

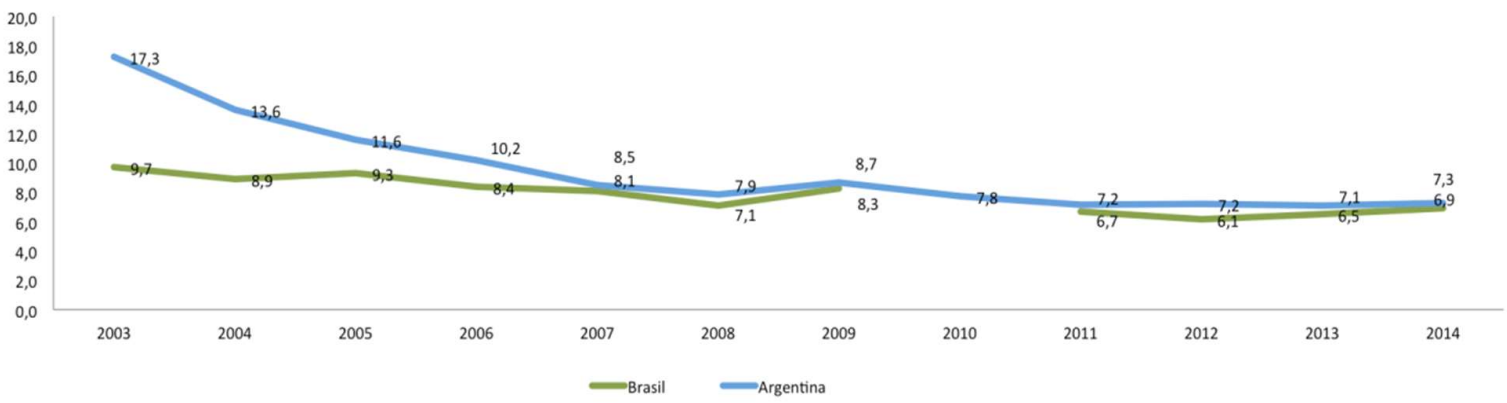

Fonte: PNAD/Argentina INDEC_EPH. : Brasil IBGE

Nota: * Não houve realização da Pesquisa Nacional por Amostra de Domicílios no Brasil no ano de 2010.

$\mathrm{O}$ aquecimento do mercado internacional no início do século XXI foi um aspecto central para a retomada do ciclo de crescimento. Em meio à explosão no preço das commodities, a desvalorização das moedas nacionais decorrente das crises cambias vivenciadas pelo Brasil em 1999 e pela Argentina em 20024 impulsionou as exportações e estimulou o crescimento do produto agregado (PIB). No caso brasileiro, a partir de 2005, os determinantes do crescimento do PIB deslocaram-se das exportações para o consumo das famílias (MEDEIROS, 2015), processo este impulsionado pelas políticas de ampliação do acesso ao crédito, pelo alargamento das transferências de renda aos mais pobres e pela política de valorização do salário mínimo. $\mathrm{O}$ aumento do consumo, por sua vez, tem impacto sobre o aumento do investimento, impulsionado também pelo crescimento do investimento público. Na Argentina, o estabelecimento do câmbio competitivo e estável criou as condições iniciais ao processo de crescimento que, nos anos seguintes, também se refletiu numa melhora da distribuição de renda, dos níveis de emprego e da redução da pobreza (DAMILL, FRENKEL e RAPETTI., 2015). Entretanto, cabe ressaltar que o impulso para a recuperação se localizou fundamentalmente na reativação de uma ampla capacidade ociosa e na queda dos custos

\footnotetext{
4 Note-se que, na Argentina, o fim do modelo de conversibilidade revelou o esgotamento de um regime econômico e político que teve consequências devastadoras para a classe trabalhadora, ao mesmo tempo em que expressava uma crise de legitimidade/governabilidade. Como afirmam Grigera e Eskenazi (2013, p. 168), a crise de acumulação sob conversibilidade também significou a crise de um modo de dominação.
} 
laborais num mercado de trabalho marcado pela condição de precarização (GRIGERA e ESKENAZI, 2013). O estabelecimento de um câmbio alto incentivou o processo de substituição de importações em alguns setores da indústria manufatureira, o que, ao lado da dinâmica exportadora, contribuiu para a recuperação da produção agregada.

O maior patamar de crescimento do PIB refletiu não somente na redução das taxas de desemprego e no aumento dos salários, mas também no incremento dos empregos formais em ambos os países (BALTAR, 2014; BECCARIA et al. 2015). No ano de 2009, Brasil e Argentina sentiram os efeitos da crise financeira internacional, o que se refletiu na queda do crescimento e no aumento das taxas de desemprego (Gráficos 1 e 2). No entanto, a adoção de uma séria de medidas anticíclicas reduziu os impactos da crise nos países ${ }^{5}$.

O ciclo de bonança vivido por ambos os países começa a se reverter a partir do ano de 2011, dando lugar a um menor ritmo de crescimento econômico que, a partir de 2013, impacta negativamente os indicadores de mercado de trabalho. Tendência esta que tem se confirmado ao longo dos anos 2015, 2016 e 2017. A situação fiscal cada vez mais deteriorada das economias atrelada a mudanças na orientação da política macroeconômica são aspectos comuns que ajudam a entender o porquê da reversão do ciclo. Assim, em 2014, a taxa de crescimento do PIB ficou em $0,1 \%$ no caso brasileiro e $0,5 \%$ no caso argentino (Gráfico 1 ). Em ambos os países, o menor ritmo de crescimento econômico entre os anos 2011 e 2014 demorou a atingir o mercado de trabalho. Isso se deve ao menor ritmo de crescimento da População Economicamente Ativa em um cenário de diminuição do ritmo de geração de novas ocupações. A taxa de desemprego só começa a aumentar entre os anos 2013 e 2014, quando o indicador passa de $7,1 \%$ para $7,3 \%$ no caso argentino e de $6,5 \%$ para $6,9 \%$, no caso brasileiro ${ }^{6}$.

A geração de emprego e renda e o crescimento dos processos de assalariamento e formalização são movimentos inegáveis ao longo dos anos 2003 e 2014, e representaram uma melhoria significativa na qualidade de vida dos trabalhadores brasileiros e argentinos. Ainda assim, questiona-se se os avanços apresentados significaram ou não uma reversão na trajetória de flexibilização laboral aprofundada nos anos 1990 em ambos os países.

Considerando que a flexibilização das relações de trabalho consiste, de acordo com Krein (2007), na tendência à ampliação da liberdade do empregador em estabelecer as condições de uso, contratação e remuneração do trabalho, é possível encontrar indícios de continuidade desse processo, seja no âmbito da negociação coletiva, seja no da regulação pública do trabalho, para ambos os países analisados.

No que se refere aos aspectos centrais da relação de emprego, é possível perceber algumas distinções quando se tratam os casos brasileiro e argentino. No primeiro, a continuidade na tendência de flexibilização das relações de trabalho manifesta-se na valorização da remuneração variável, na intensificação da jornada de trabalho e no crescimento das formas disfarçadas de emprego, com destaque para a terceirização, a despeito do aumento do emprego formal ${ }^{7}$. No segundo caso, é possível visualizar importantes avanços

\footnotetext{
5 Dentre elas a manutenção da política de valorização do salário mínimo, o fortalecimento dos bancos públicos, e o aumento do investimento público para o caso brasileiro, e a concessão de subsídios ao setor empresarial através do Programa de Recuperación Productiva (REPRO) no caso argentino.

6 No Brasil, essa tendência vem se aprofundando nos anos recentes. Conforme a PNAD contínua, a taxa de desemprego saltou de 6,5\% para 9\% entre o último trimestre de 2014 comparado com o mesmo período de 2015. No mesmo período de 2016, essa taxa era de 12\%. No caso Argentino, embora os dados sejam pouco confiáveis, a tendência é de aumento da taxa de desemprego (o próprio Ministério de Trabalho adverte que as séries estatísticas publicadas a partir de 2007 devem ser utilizadas com cautela). Segundo essas estatísticas, a taxa de desemprego já teria atingido a casa de $9 \%$ em 2016. De toda maneira, conforme apontam os relatórios da OIT e da CEPAL (2016), as taxas de crescimento do trabalho assalariado e do emprego formal estão diminuindo gradativamente em ambos os países.

${ }^{7}$ Para uma discussão detalhada a respeito ver Colombi (2018).
} 
na legislação trabalhista que limitaram substancialmente a flexibilização das relações de trabalho consolidadas nos anos 1990. Entretanto, é possível identificar, também, linhas de continuidade que se expressaram na não reversão das cláusulas outrora aprovadas e na presença de novas cláusulas de flexibilidade do trabalho nos acordos coletivos assinados durante o período estudado.

No Brasil, entre os anos 2003 e 2014, não ocorreu uma reforma trabalhista no sentido da revisão da Consolidação das Leis do Trabalho (CLT), mas alguns aspectos permitiram a permanência do processo de flexibilização.

O primeiro deles é a valorização das formas de flexibilização da remuneração. Krein e Teixeira (2014) mostram que os avanços nas negociações coletivas nos anos 2000 concentraram-se na remuneração do trabalho, com destaque para os reajustes salariais e, principalmente, os Programas de Remuneração Variável. Do ponto de vista legislativo, a aprovação da Lei 12.832 em 2013, que isenta de imposto de renda de pessoa física o recebimento de até 6 mil reais em forma de remuneração variável, veio justamente no sentido de corroborar essa prática, o que, segundo Krein e Biavaschi (2015), é uma medida de caráter flexibilizador uma vez que reduz a contribuição para a constituição de um fundo público e estimula a luta pela ampliação não do salário direto, mas da participação nos lucros.

O segundo aspecto onde a permanência da flexibilização se apresenta é a intensificação da jornada de trabalho, uma vez que ela se apresenta mais flexível, adensada e fluida (DAL ROSSO, 2008; DIEESE, 2009), a despeito da redução do número de pessoas trabalhando além de 44 horas semanais nos anos 2000 (RÁO, 2013). O estudo realizado pelo DIEESE em 2009 mostra que aos meios tradicionais de flexibilização da jornada, como hora extra, trabalho em turno, trabalho noturno, férias coletivas, somaram-se novas formas, como a jornada em tempo parcial, o banco de horas e o trabalho aos domingos. Algumas medidas no campo da legislação trabalhista reforçaram esses movimentos, tais como a Portaria do Ministério do Trabalho e Emprego, que autorizaram a redução do intervalo intrajornada por meio de negociação coletiva (2007), o Projeto de Lei que majorou a jornada de trabalho dos motoristas e reduziu o intervalo de descanso (2014) e a ratificação da possibilidade de trabalho aos feriados e domingos para os comerciários (2007).

Um terceiro aspecto é o crescimento das formas disfarçadas de emprego. Como mostram Krein e Castro (2015), a contratação como pessoa jurídica e como falso cooperativado cresceu entre os anos 2004 e 2013. Outras formas, como o estágio, foram incentivadas pela legislação trabalhista aprovada, a exemplo da Lei do $1^{\circ}$ Emprego (2004). Além disso, também houve a regulamentação das cooperativas de trabalho (2012) e da possibilidade de contratar o trabalhador que presta serviços intelectuais como Pessoa Jurídica (2005). A modalidade de emprego disfarçado que mais vem crescendo é a terceirização. Esse é um elemento que evidencia como a precarização do trabalho pode ser corroborada por novas modalidades de contratação, a despeito do crescimento do emprego formal ocorrido no período. A metodologia desenvolvida pelo DIEESE em 2017, a partir dos dados da RAIS, mostra que entre 2007 e 2014 o total de vínculos formais nessas atividades cresceu de 8,5 para 12,5 milhões.

Pode-se perceber até aqui que a via legislativa permitiu a elaboração de medidas favoráveis à classe trabalhadora, cuja maior expressão é a Política de Valorização do Salário Mínimo, mas também foi um espaço de aprovação dos aspectos flexibilizadores, como os acima pontuados. Além desses, a aprovação da reforma da previdência em 2003 é mais um elemento que reforça o enfraquecimento da rede de proteção social, uma vez que instituiu os fundos de pensão e aumentou o limite de idade dos servidores públicos para a obtenção da aposentadoria.

Na Argentina, Palomino (2008) observa que nos anos 2000 se configurou um novo regime de emprego que se contrapôs ao regime de flexibilização laboral vigente durante o 
período de conversibilidade. Sua leitura se sustenta em uma série de normativas aprovadas a partir do ano de 2003, que visaram alargar o arcabouço legal de proteção do trabalhador. Dentre as medidas aprovadas nesta direção se destacam a convocatória do Consejo Nacional del Empleo, la Productividad y el Salario Mínimo, Vital y Móvil (SMVN) e as modificações introduzidas na Ley de Ordenamiento Laboral (25.877) que revogaram a Lei 25.250, um emblema do processo de flexibilização promovido nos anos 1990. Além dessas medidas, houve a revogação do artigo 141 da Lei 24.013 que previa que o salário mínimo não poderia tornar-se base para a determinação de outros salários e a aprovação das Leis 26.390 e 26.427 que, respectivamente, regulamentaram o uso do trabalho infantil e de adolescentes e impuseram limites ao sistema de estágios. A modificação da Ley de Contrato de Trabajo (LCT) também foi um avanço importante, na medida em que passou a considerar irrenunciáveis as condições pactuadas nos contratos individuais de trabalho, estipulando restrições em caso de violação da jornada em contratos de tempo parcial e determinando um percentual máximo de trabalhadores passíveis de contratação nesta modalidade.

Marticorena (2014) propõe alguns contrapontos a esta perspectiva, ressaltando que apesar do Estado ter parado de promover medidas de flexibilidade na pós-conversibilidade, vários mecanismos continuam reafirmando essa tendência, principalmente por meio da manutenção de cláusulas de flexibilização no bojo de processos de modificação da legislação. Tal é o caso da Ley de Ordenamiento Laboral, cujas modificações limitam, mas mantêm o período probatório regulado pela Lei $\mathrm{n}^{\mathrm{o}} 24.465$, de 1995 , que permite a possibilidade de dispensa imotivada sem direito à indenização. Além disso, não se estabeleceram mudanças no que se refere à limitação do direito de greve no caso de "serviços essenciais". Da mesma forma, em 2004 foi modificada a lei das prestações familiares ${ }^{8}$ excluindo as horas extras e o salário anual complementar (Decretos 1.691/2004; 1,134/2005; 33/2007; 1.345/2007; 1.591/2008), sendo que seu carácter universal não foi restaurado. Além disso, em 2012 houve uma modificação adicional (Decretos 1667 e 1668/2012) que passou a considerar a renda familiar para o cálculo do recebimento das prestações, ocasionando a exclusão de um grande número de trabalhadores.

$\mathrm{O}$ Régimen de ordenamiento de la reparación de los daños derivados de los accidentes de trabajo y enfermedades profesionales (Lei 26.773) merece uma menção especial. Essa lei foi sancionada em 2012, alterando uma lei sobre os riscos do trabalho que vigorava desde 1995. Nos anos 1990 a lei veio para consolidar uma reforma trabalhista de caráter flexibilizador no que tange ao que era considerado um trabalho que oferecia riscos. Essa lei acabou sendo revogada pela Corte Suprema de Justicia de la Nación no ano de 2004. Essa revogação significou que o trabalhador poderia recorrer à instancia civil, requerendo uma indenização à Aseguradora de Riesgos del Trabajo (ART) e, ainda, processar o empregador no âmbito da Justicia Laboral. Em 2012, com a aprovação da nova lei, o governo acabou cedendo à demanda dos empregadores, mantendo a existência de uma lista que reconhecia as doenças consideradas e reconhecidas como geradas pela situação laboral. Além disso, inovou ao estabelecer um sistema no qual o trabalhador, uma vez indenizado pela ART, não pode processar o empregador perante a Justicia Laboral (MARTICORENA, 2015).

Em relação à negociação coletiva na Argentina, cabe assinalar o aumento da quantidade de acordos, sobretudo a partir de 2006, bem como uma alteração importante no conteúdo das cláusulas. Enquanto na década de 1990 se expandiram os acordos com conteúdo flexibilizador (NOVICK e TRAJTEMBERG, 2000), a partir de 2003 a negociação de cláusulas salariais se apresentou como o conteúdo predominante, tendo em vista o impacto da desvalorização cambial sobre o nível de preços e o poder de compra dos salários

\footnotetext{
${ }^{8}$ As prestações familiares são uma quantia em dinheiro (montantes fixos de natureza não remunerativa) que os trabalhadores assalariados recebem para cobrir os custos de seus dependentes. Eles fazem parte do sistema de seguridade social sob responsabilidade do Estado.
} 
(PALOMINO e TRAJTEMBERG, 2006). Outra característica da negociação coletiva durante a pós-conversibilidade foi o aumento dos acordos coletivos por empresa, resultando em maiores níveis de heterogeneidade das condições de trabalho. Ademais, é neste tipo de acordo que se pode verificar a maior presença de medidas que dão continuidade ao conteúdo de flexibilização dos aspectos centrais da relação de emprego, tais como as disposições sobre a jornada de trabalho, remuneração e formas de contratação (MARTICORENA, 2014; ODS, 2008).

Os argumentos levantados indicam que a flexibilização é um processo que apresenta traços de continuidade nos mercados de trabalho brasileiro e argentino, pois as modificações na legislação laboral não lograram desconstruir e, em alguns momentos, reforçaram o entulho flexibilizador presente em ambos os países. No Brasil, as evidências desse processo estão na valorização da remuneração variável, na intensificação da jornada de trabalho e no espraiamento da terceirização. No caso argentino, a valorização da remuneração variável, a vinculação da jornada ao nível de produção com turnos rotativos, a existência crescente de acordos coletivos por empresa evidencia a permanência de cláusulas flexibilizadoras, principalmente ao nível da negociação coletiva. Diante desse cenário, interessa discutir agora como as principais centrais sindicais dos países analisados (CUT e CGT) se posicionaram e procuraram disputar essas questões.

\section{A ATUAÇÃO DA CUT E DA CGT ENTRE OS ANOS 2003 E 2014}

\subsection{O caso brasileiro}

Após uma década de retirada de direitos da classe trabalhadora e de retrocessos para o movimento sindical, os anos 2000 abriram um cenário de possibilidades para a ação coletiva. Nos governos petistas, a atuação institucional da CUT $^{9}$ aprofundou-se, levando alguns estudiosos do tema, como Cardoso (2013), a afirmar que em 2003 a Central havia chegado ao poder com Lula, tornando-se um manancial de novas elites de extração popular aptas à gestão do Estado capitalista e à viabilização da utopia dos trabalhadores brasileiros: o trabalho assalariado regulado pelo Estado. Nesse período, a CUT se viu diante de um dilema: por um lado, defender os interesses da classe trabalhadora e, por outro, assumir um papel de base de sustentação do governo, amenizando e relativizando as críticas às medidas adotadas. Os embates internos e as críticas externas foram tão significativas que, a partir de 2003, a CUT sofreu um processo de cisões com a saída de correntes minoritárias que deram origem a outras centrais $^{10}$.

Distintas interpretações surgiram acerca da relação das centrais sindicais com os governos petistas, desde a tese da recuperação (BOITO e MARCELINO, 2010), passando pela ideia de moderação política do movimento (GALVÃO, 2010; 2016; ARAÚJO e VÉRAS DE OLIVEIRA, 2014) até a hipótese da cooptação sindical (DRUCK, 2006; BRAGA, 2012). Boito e Marcelino (2010) e Cardoso (2013) destacam a atuação das principais centrais sindicais ao nível das conquistas econômicas da classe trabalhadora. As demais análises mostram, entretanto, que outros aspectos precisam ser levados em consideração quando se interpreta o resultado da ação das instituições sindicais de cúpula, sobretudo ao se considerar

\footnotetext{
9 A CUT sempre teve identidade política com o PT. A Central foi criada em 1983 e sua criação se deu mediante a aglutinação das mesmas forças políticas que engendraram a formação do partido três anos antes. Atualmente a CUT é a maior central sindical brasileira e seus maiores setores de influência são: metalúrgico, bancário, setor público, rural e educação. Para uma discussão aprofundada sobre a estratégia de atuação da CUT nos governos do PT ver Colombi (2018).

10 Este foi o caso da Coordenação Nacional de Lutas (CONLUTAS) criada em 2004, da Intersindical, criada em 2006 e da Central dos Trabalhadores e Trabalhadoras do Brasil (CTB) criada em 2007.
} 
que elas atuam no cenário político (CARDOSO, 2003). Dentre estes outros fatores de análise - para além da questão econômica -, estão a relação entre o governo e o movimento sindical e a capacidade de influência das centrais na regulamentação pública do trabalho. Com o objetivo de conectar esses três aspectos, busca-se, a seguir, realizar uma análise da ação da maior central sindical brasileira. Com esse propósito, analisa-se como os temas relativos à remuneração, jornada de trabalho e formas de contratação foram encaminhados e disputados pela CUT, a fim de que se possa caracterizar o sentido das posições tomadas pela central visà-vis à necessidade de compor a base de sustentação dos governos petistas.

\subsubsection{Remuneração}

Em torno da remuneração, quatro pontos centrais estiveram em disputa durante o período analisado: a criação de uma política de valorização do salário mínimo (SM), a correção da tabela do imposto de renda (IR), a implementação do crédito consignado e a isenção de imposto de renda sobre a remuneração variável.

Quando da eleição de Lula à Presidência da República, a Central identificou a possibilidade de fortalecer a necessidade de recuperação do salário mínimo, até porque o próprio programa de governo propunha o crescimento da massa salarial como o motor da política de crescimento (PROGRAMA, 2002). Neste sentido, esperava-se que no Dia do Trabalhador do ano de 2003 o novo governo anunciasse um salário-mínimo com significativo reajuste em termos reais. O esperado não ocorreu nem em 2003 nem em 2004, o que levou a CUT a dar centralidade ao tema em seu $8^{\circ}$ Congresso Nacional, pontuando a necessidade de criação de uma Campanha Nacional pela Valorização do Salário Mínimo. Esta pauta e a correção da tabela do IR com ampliação das faixas de desconto para os assalariados conformaram o eixo das duas primeiras Marchas da Classe Trabalhadora realizadas nos anos de 2004 e 2005.

Como resultado da pressão exercida pela CUT e pelas outras centrais, em $2004 \mathrm{o}$ governo anunciou um aumento de $8,23 \%$ acima da inflação que passaria a valer a partir do ano seguinte, bem como a aprovação da correção da tabela do IR em 10\%, o que desonerava os salários de quem ocupava as faixas imediatamente superiores do mínimo. Em 2005, o movimento conquistou a antecipação do reajuste para o dia $1^{\circ}$ de janeiro de todo o ano (o que começaria a valer em 2010) e em 2006 o reajuste permanente do salário mínimo passou a seguir a fórmula correspondente à inflação do ano anterior acrescida do índice de crescimento do PIB. Em 2011, a política permanente de valorização do salário-mínimo foi aprovada, garantida até 2015 e transformada em lei. Em termos reais, o SM obteve um ganho da ordem de 76\% (DIEESE, 2015).

A partir de 2006, quando do $9^{\circ}$ Congresso Nacional da CUT, a pauta relativa à valorização do trabalho foi acrescida da luta pelo incentivo às políticas de Participação nos Lucros e Resultados (PLR). As resoluções dos congressos nacionais da CUT dos anos de 2006, 2009 e 2012 mencionam essa questão, enfatizando que a participação nos lucros e resultados é um dos canais de fomento da distribuição de renda. A CUT pautou esse ponto através da reivindicação da isenção de imposto de renda na PLR. Tal reivindicação foi atendida e transformada em lei em 2013 (Lei 12.832), isentando do IR de pessoa física o recebimento de até 6 mil reais em forma de PLR. Embora tal medida represente, de fato, o aumento do poder de compra dos trabalhadores, ela também possui caráter flexibilizador, como discutido na seção anterior.

Por fim, e ainda em consonância com a estratégia governamental de massificação do consumo, a CUT priorizou a luta por políticas públicas de incentivo ao crédito. Neste sentido, a Central iniciou um processo de negociação com instituições financeiras a fim de conquistar taxas de juros diferenciadas para os trabalhadores, e propôs ao Governo Federal a adoção de medidas que possibilitassem a reestruturação de suas dívidas. Tal reivindicação foi atendida 
via regulamentação do crédito consignado (Lei 10.820 de 2003), modalidade que autoriza empréstimos a trabalhadores mediante desconto salarial e que foi estendida para os servidores públicos e aposentados e pensionistas do Instituto Nacional de Seguro Social (INSS) (Lei 10.953 de 2004).

Sem dúvida, o crédito consignado representa o aumento do poder de consumo do trabalhador. Entretanto, por prever o desconto do salário, esta modalidade afronta o princípio da intangibilidade salarial, colocando um terceiro na relação entre o empregador e o empregado com a finalidade de "penhorar" parte do salário e torná-lo fonte de rentabilidade garantida das instituições financeiras (KREIN e BIAVASCHI, 2015). Esta questão nunca foi pontuada pela CUT, e a Central também não se propôs a debater as implicações dessa medida. Para Lavinas (2014), a atual expansão do crédito no Brasil esteve associada não somente à lógica do aumento do consumo, mas visou atender à lógica da financeirização, beneficiando instituições financeiras e transferindo do Estado para o cidadão, via acesso ao crédito privado, a gestão dos riscos embutidos em sua vida.

\subsubsection{Jornada de trabalho}

A atuação da CUT não se baseou apenas em aspectos relativos à remuneração. Entretanto, as pautas relativas às mudanças na legislação laboral foram mais tímidas e, entre os aspectos reivindicados, nenhum deles foi aprovado. A principal pauta foi a redução da jornada para 40 horas semanais sem redução de salários, entendida enquanto central para o combate ao desemprego e o aumento da riqueza nacional (CONCUT, 2003).

Em 2004, a CUT em conjunto com outras 5 centrais sindicais lançou a "Campanha Nacional pela Redução da Jornada de Trabalho sem Redução de Salário", que visava somar esforços para a aprovação da Emenda Constitucional (PEC 393/01), que previa a redução do limite legal da jornada para 40 horas semanais, podendo alcançar 35 horas dois anos depois, além do estabelecimento de um valor maior de compensação para as horas extras. Essa discussão, entretanto, não conseguiu ganhar alcance nacional e tal proposta não foi efetivada.

Em 2007, a questão volta à pauta, integrando um dos pontos de consenso entre as centrais sindicais e motivando uma série de atos e marchas unificadas. Nesse ano, a CUT realizou um Dia Nacional de Lutas e um Dia Nacional de Mobilização pela redução da jornada. Em 2008, foi realizado um novo Dia Nacional de Lutas em nome da causa, mesmo ano em que as centrais entregaram um abaixo-assinado pró-redução da jornada ao Congresso Nacional. Em 2009, diante da pertinência da pauta em um contexto de crise econômica e ameaça de desemprego, uma Comissão Especial da Câmara dos Deputados aprovou relatório favorável à uma nova Emenda Constitucional (PEC 231/95) que propunha a redução da jornada para 40 horas e ainda estabelecia o aumento do valor das horas extras remunerados de $50 \%$ para $75 \%$ a mais que as horas normais. Nesse cenário, a CUT, juntamente com outras centrais, fez dessa a pauta fundamental da $6^{\text {a }}$ Marcha da Classe Trabalhadora. Em 2010, um novo Dia Nacional de Paralizações e Mobilizações (Reduz para 40 que o Brasil aumenta) foi organizado pela CUT e, em 2013, a $7^{\text {a }}$ Marcha da Classe Trabalhadora continuou pautando a necessidade de aprovação de demanda que nunca fora aprovada.

Pautas relativas a aspectos específicos da jornada de trabalho, por sua vez, avançaram, mesmo que não em sua totalidade, como é caso da promulgação da Lei 11.603, que garante uma folga no meio da semana para os trabalhadores do setor de comércio e serviços a cada dois domingos trabalhados, embora ratifique a possibilidade de trabalho aos feriados e domingos para esses trabalhadores.

\subsubsection{Formas de contratação}

A essa altura o debate acerca das pautas trabalhistas em disputa na sociedade brasileira já permite afirmar que os pontos que tocam os aspectos centrais da relação de emprego e que restringem o poder do empregador - como a alteração da jornada de trabalho - não obtiveram 
avanços significativos nos anos 2000. Esse também foi o caso das formas de contratação, cujas alterações aumentaram o caráter flexibilizador da relação de emprego ao invés de limitálas, a exemplo da aprovação da Lei do $1^{\circ}$ Emprego que concede incentivos físcais para empresas contratarem jovens por prazo determinado e da regulamentação das cooperativas de trabalho que, ao instituir o Programa Nacional de Fomento às Cooperativas de Trabalho, legitima uma forma de contratação que pode ser mais precária, em substituição a uma relação de emprego direta. Outro ponto ainda mais importante, a terceirização, não foi vencida e, após o Golpe Parlamentar que retirou a Presidenta Dilma Rousseff do Poder Executivo, a regulamentação irrestrita da terceirização foi aprovada.

No $8^{\circ}$ Congresso Nacional da CUT, em 2003, a Central reconheceu que suas ações de combate à terceirização ainda eram muito incipientes (CONCUT, 2003). Assim, após a apresentação do Projeto de Lei 4330 de Sandro Mabel (PL), em 2004, propondo a terceirização praticamente sem restrições (BIAVASCHI e DROPPA, 2014), a CUT criou um Grupo de Trabalho. Deste grupo surgiu uma proposta de lei (PL 1621) apresentada em 2007 pelo Deputado Federal Vicente Paulo da Silva (PT), que propôs igualdade de direitos entre terceirizados e trabalhadores diretos, a proibição da terceirização em atividades fins e a responsabilidade "solidária" do contratante.

A estratégia de atuar no âmbito do legislativo fora desenhada ao lado de outras duas frentes de atuação: a tentativa de organização e representação dos trabalhadores terceirizados e de negociação e contratação coletiva com os empregadores. A CUT também atuou junto ao Grupo de Trabalho Quadripartite instalado pelo MTE e lançou uma "Campanha Nacional de Combate à Terceirização, Precarizar Não!” em 2009. Neste mesmo ano, a $6^{\mathrm{a}}$ Marcha da Classe Trabalhadora, que contou com a presença de todas as centrais sindicais reconhecidas, levou à necessidade de regulamentação da terceirização para as ruas. Em 2011, a CUT realizou um Dia Nacional de Mobilização em Defesa da Classe Trabalhadora também com essa pauta.

A ação das centrais sindicais conseguiu barrar as tentativas de votação do PL 4330/04 em diferentes momentos. Em 2013, frente à ameaça iminente de sua aprovação, a CUT realizou um Dia Nacional de Lutas e uma Ocupação no Congresso Nacional juntamente com outras centrais pressionando pela retirada do PL da pauta do Congresso Nacional. Essas tentativas foram vitoriosas até 2014. No ano seguinte, o esgarçamento do consenso entre as centrais sindicais ${ }^{11}$ e $\mathrm{o}$ aumento da pressão empresarial para a apreciação do tema desencadeou a aprovação do referido PL, que autoriza a terceirização nas chamadas atividades fim. Este PL, intitulado PLS/30, estava aguardando para ser votado no Senado Federal. Entretanto, em 2017 um antigo projeto de lei (PL 4.302/98) foi aprovado, permitindo a contratação de terceirizados em todas as atividades, isto é, sem restrições.

Dos três aspectos da relação de emprego que foram analisados, somente as reivindicações em torno da remuneração foram contempladas. Embora as mobilizações tenham constituído uma parte da estratégia sindical, como acima relatado, a ação institucional foi um eixo de atuação fundamental, sobretudo para CUT, uma vez que os espaços institucionais foram entendidos enquanto lócus privilegiado de acesso e negociação junto ao governo.

Dos três aspectos analisados, somente os pontos relativos ao poder de compra da classe trabalhadora foram efetivados. Entretanto, se todas as reivindicações tiveram os espaços de diálogo social como lugar privilegiado de negociação direta com o governo e com o patronato, por que as de cunho econômico avançaram e as que diziam respeito ao alargamento da legislação laboral não se realizaram?

\footnotetext{
${ }^{11}$ A Força Sindical se posicionou a favor do PL 4330, sendo que sua principal liderança (Paulinho da Força) revelou-se um dos principais articuladores em favor de sua aprovação (VÉRAS DE OLIVEIRA, 2015). Para mais a respeito da relação entre CUT e FS durante os governos do PT ver Krein et al. (2015) e Colombi (2018).
} 
As centrais sindicais - sob hegemonia da CUT - participaram dos espaços tripartites de negociação, com destaque para o Fórum Nacional do Trabalho (FNT), o Conselho Nacional de Relações de Trabalho (CRT) e o Conselho Nacional de Desenvolvimento Econômico e Social (CDES). As possibilidades de consensos em torno da pauta trabalhista nesses espaços foram, entretanto, limitadas. No caso do FNT, que começou pela discussão da reforma sindical, nem mesmo as demandas históricas da classe trabalhadora - liberdade e autonomia sindicais - foram alcançadas. E isso se deu em parte pelos dissensos e disputas no interior do próprio movimento sindical (FERNANDES FILHO, 2008). Já no CRT, o movimento sindical não conseguiu determinar os pontos da pauta que seriam discutidos e sua ação ficou confinada a vetar as pautas regressivas impostas pelo empresariado (COLOMBI, 2018).

Como demonstrou Colombi (2018), a pauta trabalhista foi subordinada às reivindicações dos empresários. Quando havia acordo em torno de medidas econômicas que incentivassem a produção e o consumo, o consenso desdobrava-se em alguma medida efetiva como a política de valorização do salário mínimo, o acesso ao crédito e a redução da tabela do IR. Mas quando os pontos em pauta eram em torno da legislação laboral, o empresariado apresentava o objetivo de ampliar a flexibilização, pois somente assim seria possível "garantir uma atividade empresarial saudável, num ambiente de negócios estimulante" como afirmou Antoninho Trevisan, Diretor Presidente da Trevisan Escola de Negócios, e um dos conselheiros mais ativos do CDES (Ata da $20^{\text {a }}$ Reunião do Pleno do CDES, 5 dez. 2006, p. 6). Além de enfrentar a resistência ativa do setor empresarial, o movimento sindical também resistência por parte do governo. A fala da então Presidenta Dilma Rousseff, num encontro junto aos empresários, ilustra essa questão:

\begin{abstract}
Um dos únicos momentos em que a presidente foi aplaudida no encontro foi quando disse ser contra a redução da jornada de trabalho de 44 para 40 horas semanais, pleito defendido pelas centrais sindicais. Segundo ela, em um cenário de quase pleno emprego, "não é compreensível" diminuir o tempo de trabalho quando há dificuldade em se encontrar nova mão de obra. "Não sou a favor das 40 horas porque essa é uma questão entre trabalhadores e empresários", disse. "Não considero que isso seja pauta agora nesse momento. Acho uma maluquice a gente colocar na pauta" 12
\end{abstract}

Assim, por um lado, a atuação nos espaços institucionais - liderada pela CUT permitiu o poder de veto da bancada sindical, como ocorreu com a terceirização até 2015 . Por outro lado, o próprio governo mostrava indisposição para discutir pautas que exigissem um maior enfrentamento com a bancada patronal. Essas pautas não econômicas também não foram radicalizadas pelo movimento sindical, visto que tanto o empresariado quanto as centrais sindicais reconhecidas compunham parte importante da coalização de forças que sustentava o governo (BOITO et. al, 2015). Assim, como corrobora Ramalho et al. (2015), o movimento sindical atribuiu maior importância às questões econômicas nos espaços institucionais enquanto - mesmo sem uma reforma global no código do trabalho - as práticas flexibilizantes continuaram se espraiando pelo mercado de trabalho brasileiro. A terceirização é o maior exemplo desse processo. Em nome de uma aliança governamental e sob pena de dissolver as bases de apoio dos governos petistas, a CUT pautou sua atuação institucional nas questões econômicas, demonstrando pouca disposição para outras formas de manifestação e luta capazes de barrar os aspectos flexibilizadores das relações de trabalho que, paulatinamente, iam degradando as condições de trabalho dos trabalhadores brasileiros.

\footnotetext{
${ }^{12} \mathrm{Cf} . \quad<$ http://www1.folha.uol.com.br/poder/2014/05/1451704-a-empresarios-dilma-rebate-criticas-sobresuposta-falta-de-dialogo.shtml $>$.
} 


\section{$3.2 \mathrm{O}$ caso argentino}

Assim como para a CUT, os anos 2000 conformaram um cenário singular para a atuação da CGT que logrou desempenhar um importante papel na dinâmica econômica e política da Argentina. A baixa porcentagem de votos com os quais Nestor Kirchner, candidato da $\mathrm{FPV}^{13}$, ganhou a eleição presidencial ${ }^{14} \mathrm{o}$ fez buscar apoio em vastos grupos sociais, dentre eles o movimento sindical. Neste sentido, a aliança com a CGT colocou o governo como ator central dos conflitos laborais num contexto macroeconômico marcado pelo fortalecimento dos setores industriais tradicionais, onde os sindicatos peronistas desta central são protagonistas (ETCHEMENDY e COLLIER, 2008) ${ }^{15}$.

A ligação entre a CGT e a FPV foi marcada por uma lógica de concessões e negociações através das quais o Estado deu poder ao setor da CGT liderado por Hugo Moyano, promovendo a unificação da Central sob sua liderança. Em contrapartida o referido líder sindical garantiu a contenção da luta distributiva (MARTICORENA, 2015). Entretanto, diversas vicissitudes marcaram a relação do governo com a Central, levando-a a dividir-se em duas.

A primeira divisão deu-se no ano de 2008 e ocorreu em meio ao denominado "conflito do campo"16. A presença de um setor que defendia os interesses do setor agropecuário no interior da CGT levou à formação da CGT Azul y Blanca, liderada por Luis Barrionuevo. O setor que permaneceu sob a liderança de Hugo Moyano manteve-se como base de apoio do governo ${ }^{17}$.

A segunda divisão ocorreu em 2012, e se vincula com as tensões existentes entre o próprio Moyano e o governo. A partir do segundo mandato do governo de Cristina Fernández, iniciado no ano de 2010, os ruídos entre o setor da CGT liderado por Moyano e a FPV se agudizam. Assim, como assinala Patroni (2016), as demandas do dirigente sindical se referiam principalmente ao seu posicionamento descolado das estruturas do Partido Justicialista $(\mathrm{PJ})^{18}$. Esse processo também se expressou no afastamento da ala sindical da estrutura partidária, ao passo que se produziu uma aproximação e um fortalecimento do grupo denominado La Cámpora ${ }^{19}$ como base social da FPV. Como resultado, em 2012, é formada a CGT Azopardo, liderada por Hugo Moyano, que passa a fazer oposição ao governo. Já a CGT Oficial ficou sob a condução do dirigente da Unión Obrera Metalúrgica (UOM), Antonio Caló. Este último setor manteve uma estratégia conciliadora com o governo, enquanto que a CGT Azopardo, como veremos nas linhas seguintes, passou a exercer um papel político de oposição.

\footnotetext{
13 A FPV é uma frente eleitoral composta pelo peronismo organizado da Província de Buenos Aires. Embora o Partido Justicialista (PJ) seja majoritário na formação da FPV, a Frente também reúne outros setores. Para uma análise das características e composição da FPV, ver Rocca Rivarola, 2011.

14 Nestor Kirchner tornou-se presidente com 22,5\% dos votos, após o ex-presidente Carlos Menem renunciar à candidatura quatro dias antes do segundo turno das eleições.

${ }^{15}$ Para uma discussão aprofundada a respeito ver D'Urso (2017).

16 O "conflito do campo" foi um lock out patronal convocado pelo setor empresarial contra a Resolução 125/2008 que estabelecia um sistema de retenções móveis aos impostos aplicados sobre a soja e outros cereais destinados à exportação.

17 Esse conflito também levou a disputas no interior da Central de Trabajadores de la Argentina (CTA) que, mais tarde resultaram em sua fração. No ano de 2010, a CTA dividiu-se num setor liderado por Hugo Yasky (Confederación de Trabajadores de la Educación de la República Argentina - CTERA) e outro por Pablo Micheli (Asociación de Trabajadores del Estado - ATE).

18 Historicamente, a CGT aparece como um ator-chave na cena política nacional, particularmente na estrutura partidária do peronismo, até constituir-se em um grupo central dentro do PJ fundado por Juan Domingo Perón em 1947. Para mais, ver Senén González e Fabián Bosoer, 2009.

19 "La Cámpora" é um dos grupos mais importantes da militância kirchnerista que nucleia principalmente a juventude (VÁZQUEZ e VOMMARO, 2012).
} 
O protagonismo da CGT, refletido, ao menos até 2012, em seu papel na defesa do modelo econômico e político do kirchnerismo, ensejou análises que caracterizam a dinâmica sindical argentina como um processo de revitalização. Senen Gonzalez e Haidar (2009) apontam que o aumento da negociação coletiva, da taxa de sindicalização e das disputas trabalhistas expressa o protagonismo dos sindicatos tradicionais nos anos recentes. Assim, algumas perspectivas enfatizam a centralidade das lideranças sindicais tradicionais que - num contexto marcado pelo crescimento econômico e a melhora nos indicadores no mercado do trabalho - conseguiram negociar salários acima da inflação (ETCHEMENDY e COLLIER, 2008; SPALTENBERG, 2012). Ao mesmo tempo, outras visões críticas destacam o surgimento e desenvolvimento de experiências sindicais de base e antiburocráticas que, além do salário, também disputaram questões relacionadas às condições de trabalho e às formas de contratação (ATZENI e GHIGLIANI, 2013; VARELA, 2013). Apesar destes argumentos, a tese da revitalização pode ser relativizada: a prevalência de práticas de filiação sindical tradicionais sobre aquelas que promoveram algum tipo de inovação e, ainda, a prioridade à ação institucional e à colaboração que caracterizaram as práticas dos principais sindicatos são alguns dos elementos que permitem questionar a natureza renovadora das estratégias sindicais (MARSHALL e PERELMAN, 2008).

Sem dúvida, as alterações no contexto econômico e o papel assumido pela CGT criaram as bases para o aprofundamento da atuação institucional. No entanto, o aumento quantitativo dos indicadores de poder sindical (negociação coletiva, taxa de sindicalização e disputas trabalhistas) não expressam per si a presença de um processo de revitalização. Em vez disso, indaga-se sobre os sentidos das práticas e discursos mobilizados pelos atores. Pergunta-se, assim, que ações foram encabeçadas pela CGT entre os anos 2003 e 2014 com o objetivo de influenciar a agenda laboral do kirchnerismo, bem como qual a posição assumida pela Central frente às principais disputas em torno dos aspectos que conformam a relação de trabalho.

\subsubsection{Remuneração}

Depois da desvalorização do ano 2002, a recuperação do poder de compra dos salários foi uma questão central na agenda laboral da CGT, e tomou forma através de quatro pontos principais: o salário mínimo, as negociações salariais, o imposto de renda e as prestações familiares. Por sua parte, a participação dos trabalhadores nos lucros foi um dos fatores que, em 2010, gerou ainda mais tensões entre o governo e a CGT.

As disputas sobre o salário mínimo começaram antes da chegada de Néstor Kirchner à presidência. Durante os governos que seguiram a crise de 2001, a convocatória para o Consejo Nacional del Empleo, la productividad y el Salario Mínimo Vital y Móvil foi um tema recorrente em relação ao qual a CGT teve uma atitude ofensiva. No entanto, durante a primeira negociação no âmbito do Conselho do Salário convocada em 2004, a Central deixou claro qual seria o seu papel. Embora inicialmente a CGT estivesse alinhada à reivindicação da CTA (Central de Trabajadores de la Argentina) exigindo um mínimo de \$730, ela acabou aceitando os $\$ 450$ propostos pelo governo e que estavam mais próximos dos $\$ 424$ considerados pelo setor empresarial representado pela UIA (Unión Industrial Argentina). Assim, a CGT dava sinais de adoção de uma estratégia político-sindical moderada durante os primeiros anos do governo, em troca de se posicionar como o principal interlocutor entre o governo e o movimento sindical (PAYO ESPER, 2015).

Neste contexto de rearticulação da relação do Estado com a CGT liderada por Moyano, a promulgação da Ley de Ordenammiento Laboral em 2004 apresentou dois aspectos importantes em termos dos recursos de poder sindical: a restauração do princípio de 
ultratividade ${ }^{20}$ e a importância atribuída à negociação coletiva de nível superior; aspectos que fortaleceram o papel da CGT nas negociações coletivas. Assim, entre 2004 e 2007, os sindicatos tradicionais da CGT participaram de uma série de acordos salariais ao nível das cúpulas sindicais com o governo e os empresários. Estas negociações tripartites resultaram em aumentos salariais para os trabalhadores do setor formal, embora limitados aos objetivos antiinflacionários do governo (ETCHEMENDY e COLLIER, 2008). Além disso, destaca-se o papel do sindicato de motoristas de caminhões ("Camioneros"), liderado por Moyano, que estabeleceu um padrão de negociação que passou a ser replicado nos setores restantes.

Em 2010, atravessado o impasse da crise internacional, Cristina Kirchner começou seu segundo mandato num contexto de recuperação econômica. Naquele mesmo ano, o Deputado do FPV, Hector Recalde - que até então era também advogado da CGT -, apresentou na Câmara dos Deputados um projeto sobre a participação dos trabalhadores nos lucros das empresas. $\mathrm{O}$ projeto não teve muito eco no Parlamento, principalmente devido às resistências por parte das empresas representadas pela UIA, mas também pelo governo. Em 2011, na $17^{\circ}$ Conferência Anual da UIA, a presidenta anunciou o início de uma nova etapa na política econômica, a fase da "sintonia fina", marcada pelo impulso à produtividade e ao investimento (PATRONI, 2016). Nesta ocasião, ela também descartou a lei da participação dos trabalhadores nos lucros, sugerindo que a discussão deveria ser resolvida no âmbito da negociação coletiva. Estes eventos intensificaram as tensões entre Moyano e a FPV, e produziram uma nova divisão dentro da CGT em 2012.

O fim da aliança entre Moyano e o governo, a ruptura da CGT e a desaceleração do crescimento econômico abriram uma nova perspectiva na dinâmica das greves gerais e das reivindicações da Central. Em novembro de 2012, a CGT convocou a primeira greve geral do período iniciado em 2003, cujas reivindicações foram: o aumento do valor mínimo do salário sobre o qual não incidia o imposto de renda, a universalização das prestações familiares, o aumento do valor da aposentadoria em caráter de emergência para os aposentados e, por fim, que o governo reconhecesse a subdeclaração dos valores inflacionários divulgados mensalmente pelo INDEC (PAYO ESPER, 2014). Em 2013, embora não tenham ocorrido greves gerais, o sindicato de motoristas de caminhões convocou uma greve e uma marcha para a Plaza de Mayo por conta do impacto do imposto sobre o salário de seus representados. Posteriormente, em abril de 2014, as centrais sindicais opositoras ao governo (CGT Azul y Blanca, CTA Micheli e CGT Azopardo) convocaram novamente uma greve geral cujas reivindicações foram "negociações salariais livres", um incremento de emergência para os aposentados e o aumento do valor mínimo sobre o qual se aplica o imposto de renda (PAYO ESPER, 2014).

As greves gerais colocaram no centro do debate dois eixos ligados à questão salarial: o imposto de renda e as prestações familiares. Em relação ao primeiro ponto, desde 2006 o governo vinha corrigindo o valor dos salários para que o aumento nominal dos mesmos não representasse uma parcela maior de salários sobre os quais incidiam o imposto de renda, bem como a incidência de taxas maiores para salários nominalmente maiores. Entretanto, a partir de 2008 tal correção ficou desatualizada em relação à inflação e, em 2012, o valor mínimo da faixa salarial sobre a qual não incidia o imposto não foi atualizado, um dos motivos que levou à greve geral neste ano. O governo, então, excluiu a incidência do imposto sobre a metade dos salários do mês de dezembro e fez uma atualização de $20 \%$ sobre o valor mínimo dos salários não tributáveis em janeiro de 2013. Mesmo assim, esta correção manteve o valor desatualizado em relação às negociações do ano anterior e permaneceu ainda maior no ano seguinte, em virtude da desvalorização do peso e dos aumentos inflacionários (MARTICORENA, 2015).

20 O princípio de ultratividade estabelece a continuidade dos acordos coletivos, mesmo se completado o seu período de cobertura, até que um novo acordo seja assinado para substituir o anterior. 
Por fim, uma questão que tem levantado algumas controvérsias diz respeito às prestações familiares. O cálculo, em função do salário nominal, dos valores a partir dos quais os trabalhadores recebem as prestações - considerando todos os salários do grupo familiar (Decretos 1667/2012 e 1668/2012) - ocasionou a exclusão de um número substancial de trabalhadores, bem como restringiu o montante daqueles que eram abrangidos pelas prestações de maior valor (CIFRA, 2012). Isto despertou o descontentamento dos sindicatos, e foi expresso na greve geral de 2012 que, dentre outras reivindicações, requereu a recuperação do caráter universal que as prestações familiares tinham, ao menos até 1996.

\subsubsection{Jornada de trabalho}

Ao contrário do Brasil, onde a questão da jornada de trabalho tem sido um dos eixos mais importantes na agenda de reivindicações da CUT, na Argentina este problema tem sido profundamente negligenciado nas disputas abertas pela CGT. Ao observar os conflitos laborais no sector privado entre 2006 e 2014, nota-se que o ritmo de trabalho, os turnos rotativos, a redução da jornada (e do salário) em momentos de crise e o prolongamento da jornada de trabalho através de horas extras são elementos presentes nas reivindicações que motivaram as ações tomadas principalmente por organizações de base (D’URSO, 2016). No entanto, estas questões, mais pontuais, não se comparam às propostas mais ambiciosas que foram discutidas no Brasil, tal qual a redução da jornada de trabalho sem redução de salários e a limitação das horas extras.

\subsubsection{Formas de contratação}

A despeito de as principais ações da CGT terem se concentrado na dimensão salarial, as formas de contratação não estiveram totalmente ausentes. No ano de 2009 , no contexto da crise internacional e em resposta às exigências dos grandes sindicatos industriais, as políticas laborais visaram à aplicação de subsídios às empresas em troca do compromisso de não demitir trabalhadores por meio do Programa de Recuperação Produtiva (REPRO). Algumas mudanças na regulação também foram feitas no sentido de conter a propagação de modalidades flexíveis de contratação, como pontuado na primeira seção.

No que se refere à terceirização, essa questão não tem sido um eixo de destaque nas reivindicações mobilizadas pela CGT, mas esteve presente ao nível parlamentar, particularmente de $2010 \mathrm{em}$ diante. Isso porque naquele ano ocorreu o assassinato de Mariano Ferreyra, militante do PO (Partido Obrero), durante uma manifestação convocada pelos trabalhadores ferroviários terceirizados da linha Roca. Respondendo ao fato, a CTA convocou uma paralização de 24 horas, enquanto a CGT se limitou a exigir que o crime fosse esclarecido e os responsáveis julgados. Além disso, Moyano se referiu aos fatos no dia seguinte afirmando que a responsabilidade do crime era das empresas terceirizadoras ${ }^{21}$.

Para além destas questões discursivas, desde 2010 foram apresentados três projetos de lei que visaram regulamentar a terceirização. No entanto, várias pressões de ordem econômica e política - particularmente aquelas expressadas pela UIA - têm dificultado o seu progresso. É importante notar que esses casos não foram acompanhados por uma mobilização da base social do partido ao qual os deputados respondem, nem das centrais sindicais aliadas a estes, o que demostra que a terceirização não foi objeto de mobilização pelas cúpulas sindicais.

\section{CONSIDERAÇÕES FINAIS}

\footnotetext{
21 Em seu discurso, Moyano não citou a responsabilidade de José Pedraza (Secretário Geral da UTA) no crime, quem em 2013 foi condenado a 13 anos de prisão como "participante necessário" dos fatos. A condenação revela não só a responsabilidade do líder sindical no crime, mas também seus laços com as empresas que terceirizam os trabalhadores do setor ferroviário (ZORZOLI, 2014).
} 
O presente artigo partiu do objetivo de identificar em que medida as principais centrais sindicais do Brasil e da Argentina lograram alterar a agenda laboral de seus respectivos governos entre os anos 2003 e 2014; ademais, indagou-se se as práticas, o discurso e os resultados da ação dessas organizações sindicais poderiam ser caracterizadas como um processo de revitalização ou recuperação sindical nesses países. Para tanto, a partir da sistematização das informações provenientes de fontes secundárias e primárias foram contextualizadas e analisadas as ações realizadas pela CUT e pela CGT em relação aos principais aspectos da relação de emprego: remuneração, jornada de trabalho e formas de contratação. A atuação das centrais no período analisado situou-se em um momento econômico e político favorável que atravessou ambos os países, como evidencia a análise dos indicadores econômicos e do emprego, marcando um novo momento para a ação sindical.

No caso brasileiro, a CUT, apostando principalmente em uma estratégia de participação institucional, logrou alcançar as reivindicações que se encontravam na esfera econômica. Já no caso da CGT, as reivindicações vinculadas à correção da tabela do imposto de renda e a recuperação do caráter universal das prestações familiares não foram conquistadas, ao passo que a valorização do salário mínimo, mesmo que não no patamar requerido, e os ganhos em negociações salariais foram alcançados. No caso argentino, a questão singular reside no fato de que as conquistas se deram antes de 2012, ao passo que as demandas que buscaram travar disputas mais intensas não foram vitoriosas, e ocorreram somente após a ruptura de parte do movimento sindical com o governo, momento em que a CGT convocou greves gerais e trouxe a agenda salarial novamente para o centro do debate.

Nos pontos que dizem respeito à jornada laboral e às modalidades de contratação, é preciso ressaltar que esses aspectos obtiveram, em ambos os casos, menos apelo do movimento sindical. No caso da CGT, pode-se afirmar que os esforços se orientaram, fundamentalmente, para a luta situada no plano das remunerações. Unicamente se distinguem algumas medidas pontuais que buscaram proteger o emprego no marco da crise internacional. No caso brasileiro, as lutas pela redução da jornada laboral e pelo fim da terceirização adquiriram espaço dentro do conjunto das demandas mobilizadas, mas as intenções da CUT não foram suficientes. Assim, se a CUT manteve alguma iniciativa nesses pontos, a CGT nem sequer inseriu demandas dessa natureza na pauta de reivindicações.

Os limites do conjunto de reinvindicações do movimento sindical argentino podem ser explicados, em grande parte, pela decisão política da CGT de não tensionar pontos da pauta trabalhista não contemplados na agenda laboral dos governos, uma vez que esta constituía a principal base de apoio social do kirchnerismo, ao menos durante os primeiros mandatos. A orientação de sua estratégia sindical esteve, assim, profundamente marcada por sua atuação institucional circunscrita no plano da negociação salarial em conformidade com as diretrizes estabelecidas pelos governos. Ademais, na medida em que a CGT identificou no crescimento econômico com geração de empregos uma conjuntura favorável à valorização real dos salários, a articulação e a aproximação direta junto aos governos assumiu um caráter estratégico para a central, e tornou-se um aspecto fundamental para a garantia das conquistas.

Enquanto na Argentina o vínculo entre a CGT e o governo foi atravessado por numerosos contrapontos que operaram como elemento decisivo na orientação das ações da central, no Brasil a relação entre a CUT e o governo manteve certa estabilidade. Do mesmo modo que a CGT, o compromisso de apoiar os governos de origem democrático-popular moderou as mobilizações e negociações em torno das bandeiras que poderiam trazer maiores desgastes à coalização política que sustentava aqueles governos, dentre elas o combate a qualquer forma de terceirização e as mobilizações e articulações em torno da redução da jornada de trabalho sem redução de salários. Sem contar com o apoio governamental e com a pressão pró-flexibilização do setor empresarial, o poder de veto da CUT conseguiu barrar a regulamentação da terceirização sem restrições, mas no mundo real essa prática continuou se 
alastrando ancorada na ausência de uma legislação amplamente limitadora. Assim, em nome do apoio aos governos eleitos e dos benefícios econômicos que essas frentes políticas poderiam trazer para a classe trabalhadora, as duas principais centrais sindicais do Brasil e da Argentina não conseguiram reverter a tendência de flexibilização das relações de trabalho ainda vigentes em ambos os países.

Uma atuação sindical situada, principalmente, no âmbito de uma luta econômica que, por sua vez, não se contrapunha à agenda governamental e nem tinha a capacidade de disputar reivindicações históricas da classe trabalhadora que pudessem questionar o poder do empregador em determinar os aspectos da relação de emprego, sobretudo no que diz respeito à jornada de trabalho e às formas de contratação, permite questionar a caracterização das estratégias sindicais como um processo de recuperação/revitalização. Mesmo com a efetivação de ganhos econômicos expressivos para a classe trabalhadora, aspecto não desprezível e de grande importância para países com alto índice de desigualdade, o comprometimento da capacidade sindical de reverter o processo de flexibilização das relações laborais marca a ausência de um processo de revitalização sindical. E, ainda mais importante, isso indica uma tendência à valorização do papel econômico do ator sindical.

\section{REFERÊNCIAS}

ARAÚJO, A.; VÉRAS DE OLIVEIRA, R. O sindicalismo na era Lula: entre paradoxos e novas perspectivas. In: VÉRAS DE OLIVEIRA. Roberto; BRIDI, Maria Aparecida; FERRAZ, M. (Orgs.). Sindicalismo na era Lula: paradoxos, perspectivas e olhares. Belo Horizonte: Fino Traço, 2014, p. 29-60.

ATZENI, M. ; GHIGLIANI, P. The re-emergence of work place based organisation as the new expression. Of conflict in Argentina. In: GREGOR G. (Ed.). New forms and expressions of conflict at work. London: Palgrave Macmillan, 2013.

BALTAR, P. Crescimento da economia e mercado de trabalho no Brasil. In: CALIXTRE, A. B.; BIANCARELli, A. M.; CINTRA, M. A. M. (Ed.). Presente e futuro do desenvolvimento brasileiro. Brasília: Ipea, 2014. p. 423-468.

; SANTOS, A.; KREIN, J. D.; LEONE, E.; MORETTO, A.; SALAS, C.; PRONI, M.; MAIA, A. Trabalho no governo Lula: uma reflexão sobre a recente experiência brasileira. Global Labour University Working Papers, Paper n. 9, p. 1-47, 2010.

BARBOSA, N.; SOUZA, J. A. P. A Inflexão do Governo Lula: política econômica, crescimento e distribuição de renda. In: SADER, Emir; GARCIA, Marco Aurelio. (Orgs). Brasil: entre o passado e o futuro. São Paulo: Fundação Perseu Abramo e Editora Boitempo, 2010.

BASUALDO, V. Los delegados y las comisiones internas en la historia argentina 1943-2007. In: SCHORR, M. et al. (Orgs.) La industria y el sindicalismo de base en la Argentina. Buenos Aires: Atuel, 2010.

BECCARIA, L.; MAURIZIO, R.; VAZQUEZ, R.; VAZQUEZ, G. Desigualdad e informalidad en América Latina: el caso de la Argentina. In: AMARANTE, V.-A. (Ed.). Desigualdad e informalidad: un análisis de cinco experiências latinoamericanas - CEPAL LC/G 2637-P, 2015, p. 89-128.

BIAVASCHI, M.; DROPPA, A. A dinâmica da regulamentação da terceirização no Brasil: as súmulas do Tribunal Superior do Trabalho, os projetos lei e as decisões do Supremo Tribunal 
Federal. Revista de Ciências Sociais Política e Trabalho, n. 41, p. 121-145, 2014.

BOITO, A.; MARCELINO, P. O sindicalismo deixou a crise para trás? Um novo ciclo de greves na década de 2000. Cadernos CRH, n. 59, p. 323-338, 2010.

BOITO JR, A.; GALVÃO, A.; MARCELINO, P. A nova fase do sindicalismo brasileiro. In: CESIT, U. (Ed.). Sindicalismo Contemporâneo: uma nova visão para o movimento sindical. São Paulo: União Geral dos Trabalhadores, 2015. p. 206-223.

BRAGA, R. A política do precariado: do populismo à hegemonia lulista. São Paulo: Editora Boitempo, Universidade de São Paulo, Faculdade de Filosofia, Ciências e Letras, 2012.

CARDOSO, A. Para onde foram os sindicatos? In: $37^{\circ}$ ENCONTRO ANUAL DA ANPOCS. Águas de Lindóia, 2013.

CDES. Ata da $20^{a}$ reunião do pleno do cdes. Disponível em: <www.cdes.gov.br>. Acesso em 15 jul. 2016.

CEPAL/OIT. Coyuntura laboral en América Latina y el Caribe. Mejoras recientes y brechas persistentes en el empleo rural. CEPAL, 2016. Disponível em:

$<$ http://www.cepal.org/es/publicaciones/40097-coyuntura-laboral-america-latina-caribemejoras-recientes-brechas-persistentes>. Acesso em 06 jul. 2016.

CIFRA. Información sobre asignaciones familiares e impuesto a las ganancias. Cómo afectan a los trabajadores. Documento de Trabajo, n. 12, CIFRA-CTA, 2012. Disponível em:

$<$ http://www.centrocifra.org.ar/publicacion.php?pid=57>. Acesso em 12 maio 2017.

COLOMBI, A. P. F. A institucionalização do consenso: atuação da CUT e da FS durante os governos do PT (2003-2014). Tese de doutorado. Instituto de Economia, UNICAMP, 2018 .

CONCUT. Resoluções do $8^{\circ}$ congresso nacional da cut. Disputar a hegemonia política visando a construção de uma nova sociedade, São Paulo, 2003. Disponível em:

$<$ http://cedoc.cut.org.br/resolucoes-de-congressos>. Acesso em 25 ago. 2015.

D'URSO, L. As disputas trabalhistas na Argentina da pós-conversibilidade: uma análise à luz dos debates sobre a revitalização sindical. Revista Ciências do Trabalho, n. 6, p. 21-65, 2016.

- ¿Renovación de las estrategias sindicales en Argentina y Brasil? Los casos del

SMATA y del Sindicato dos Metalúrgicos de ABC (2003-2014). Tesis de Doctorado, Universidad de Buenos Aires, Facultad de Ciencias Sociales, 2017.

DAL-ROSSO, S. Mais trabalho: a intensificação do labor na sociedade contemporânea. São Paulo: Boitempo, 2008.

DAMILL, M., FRENKEL, R., RAPETTI, M. Macroeconomic policy in Argentina during 2002-2013. Comparative Economic Studies, v. 57, n. 3, p. 369-400, 2015.

DIEESE. As razões para a jornada de trabalho de 40 horas, 2009. Disponível em:

$\leq$ https://cut.org.br/system/uploads/action_file_version/a7f89596704546308668d1fab3d712e1/

file/nt-2085-20set-202009-20argumentosreduzirjornada.pdf $>$. Acesso em 10 jan. 2017.

. Política de valorização do salário mínimo. Salário mínimo de 2015 fixado em R\$ 788,00, Nota Técnica, n.143, 2015. Disponível em:

$<$ http://www.dieese.org.br/notatecnica/2015/notaTec143SalarioMinimo.pdf $>$. Acesso em 15 jun. 2016.

Revista da ABET, v. 17, n. 1, Janeiro a Junho de 2018 
Terceirização e precarização das condições de trabalho, Nota técnica, n. 172, 2017. Disponível em: <https://www.dieese.org.br/notatecnica/2017/notaTec172Terceirizacao.pdf>. Acesso em 15 maio 2016.

DRUCK, G. Os sindicatos, os movimentos sociais e o governo Lula: cooptação e resistência. Debates, n. 19, p. 329-340, 2006.

ETCHEMENDY, S.; COLLIER R. Golpeados pero de pie: resurgimiento sindical y neocorporativismo segmentado en Argentina (2003-2007). Postdata, n.13, p. 145-192, 2008.

FERNANDES FILHO, H. P. A atuação do movimento sindical junto ao Fórum Nacional do Trabalho. (Dissertação) Mestrado em Sociologia - Programa de Pós-graduação em Sociologia/UNB, Brasília: UNB, 2008.

GALVAO, A. (Expositora oral). O movimento sindical no governo Lula entre a divisão e a unidade. In: VI CONGRESO DE LA ASOCIACIÓN LATINOAMERICANA DE SOCIOLOGÍA DEL TRABAJO, (20/04/2009 a 23/04/2009), Cidade do México, México.

. Political action of the Brazilian labour movement: issues and contradictions facing PT governments. Studies in Political Economy a Socialist Review, n. 96, 2016.

GRIGERA, J., ESQUENAZI, M. Apuntes sobre la acumulación de capital durante la posconvertibilidad. In: GRIGERA, J. (Comp.). Argentina después de la convertibilidad (2002-2011). Buenos Aires: Imago Mundi, 2013. p. 165-194.

HYMAN, R. Understanding european trade unionism - between market, class and society. London: Sage, 2001.

JAMES, D. Resistencia e integración. El peronismo y la classe trabajadora argentina. Buenos Aires: Sigloveintiuno Editores, 2013.

KREIN, J. D. Tendências recentes nas relações de emprego no Brasil: 1990-2005. (Tese) Doutorado em Economia Social e do Trabalho - Instituto de Economia, UNICAMP. Campinas: Universidade Estadual de Campinas, 2007.

.; BIAVACHI, M. Os movimentos contraditórios da regulação do trabalho no Brasil dos anos 2000. Revista Cuadernos del Cendes, n. 89, p. 47-82, 2015.

; CASTRO, B. As formas flexíveis de contratação e a divisão sexual do trabalho, São Paulo, Fundação Frederich Ebert, 2015. Disponível em: <http://library.fes.de/pdffiles/bueros/brasilien/12084.pdf>. Acesso em 12 set. 2016.

; DIAS, H.; COLOMBI, A. P. As centrais sindicais e a dinâmica do emprego. Estudos Avançados USP, n. 85, p. 121-135, 2015.

; TEIXEIRA, M. As controvérsias das negociações coletivas nos anos 2000 no Brasil. In: VÉRAS DE OLIVEIRA. Roberto; BRIDI, Maria Aparecida; FERRAZ, M. (Orgs.). Sindicalismo na Era Lula: paradoxos, perspectivas e olhares. Belo Horizonte: Fino Traço, 2014. p. 213-246.

LAVINAS, L. La asistencia social en el siglo XXI. New Left Review, n. 84, p. 7-48, 2014.

MARSHALL, A.; PERELMAN, L. Why "union revitalization" is not an issue in Argentina? Labour institutions and the effectiveness of traditional trade union recruitment strategies. 29TH ANNUAL CONFERENCE OF THE INTERNATIONAL WORKING PARTY ON LABOUR MARKET SEGMENTATION. Porto, 2008.

MARTICORENA, C. Trabajo y negociación colectiva. Los trabajadores en la industria argentina, de los noventa a la posconvertibilidad. Buenos Aires: Imago Mundi, 2014. 
Avances en el estudio de la relación entre sindicalismo y kirchnerismo. Sociohistórica, n. 36, p.1-22, 2015.

MCILROY, J. Ten years of new labour: workplace learning, social partnership and union revitalizations in Britain. British Journal of Industrial Relations, v. 2, n. 46, p. 283-313, 2008.

MEDEIROS, C. Inserção externa, crescimento e padrões de consumo na economia brasileira. Brasília: IPEA, 2015.

NOVICK, M.; MAZORRA, X.; SCHLESSER, D. Un nuevo esquema de políticas públicas para la reducción de la informalidad laboral. In: Aportes a una nueva visión de la informalidad laboral en la Argentina. Banco Mundial y MTEySS, Buenos Aires, 2008.

.; TRAJTEMBERG, D. La negociación colectiva en el período 1991-1999. Documento de trabajo - MTEySS, n. 19, Buenos Aires, 2000.

OBSERVATORIO DEL DERECHO SOCIAL DE LA CTA. La negociación colectiva 20032007: un estudio comparativo con el período 1991-1999, en particular sobre la regulación de jornada y organización del trabajo. Buenos Aires: CTA, 2008.

PALOMINO, H. La instalación de un nuevo régimen de empleo en Argentina: de la precarización a la regulación. Revista Latinoamericana de Estudios del Trabajo, n. 19, p. 121-144, 2008.

; TRAJTEMBERG, D. Una nueva dinámica de las relaciones laborales y la negociación colectiva en la Argentina. Revista de Trabajo del Ministerio de Trabajo, Empleo y Seguridad Social, n. 2(3), p. 47-68, 2006.

PANIGO, D.; NEFFA, J. El mercado de trabajo argentino en el nuevo modelo de desarrollo. Documento de trabajo - MTEySS. Dirección Nacional de Programación Macroeconómica, Ministerio de Economía y Finanzas Públicas, Buenos Aires, 2009.

PATRONI, V. Unionism and the rise and fall of the'leftturn' in Argentina. LASA CONGRESS 2016. New York, 2016.

PAYO ESPER. M. De los conflictos laborales a las huelgas generales. Algunos apuntes para pensar su dinámica 2002-2012 en Argentina. Sociohistórica, n. 33, La Plata, 2014.

Algunas consideraciones en torno al Salario Mínimo y a la dinámica de la CGT en el Consejo del Salario en la Argentina post-convertibilidad. Trabajo y Sociedad, n. 24, p. 95$108,2015$.

PROGRAMA de Governo, coligação Lula Presidente, 2002. Disponível em:

$<$ http://novo.fpabramo.org.br/uploads/programagoverno.pdf>. Acesso em 17 fev. 2015.

RÁO, E. Tempo de trabalho no Brasil Contemporâneo: a duração da jornada de trabalho (1990-2009). (Dissertação) - Mestrado em Desenvolvimento Econômico, Programa de PósGraduação em Economia Social e do Trabalho. Campinas: UNICAMP, 2013.

RAMALHO, J. R.; CORDEIRO, M. de C.; SILVA, E. Movimento sindical, conselhos e participação social: estudo de caso sobre a dinâmica no Brasil após a era Lula. II ENCONTRO INTERNACIONAL PARTICIPAÇÃO, DEMOCRACIA E POLÍTICAS PÚBLICAS. Campinas, 2015.

ROCCA RIVAROLA, D. En torno al líder: Relaciones y definiciones de pertenencia dentro de los conjuntos oficialistas de Luiz Inácio Lula da Silva (2002-2006) y Néstor Kirchner (2003-2007). Tesis doctoral. Buenos Aires: Facultad de Ciencias Sociales, UBA, 2011. 
RODRIGUES, I. J.Sindicalismo e política: a trajetória da CUT (1983 a 1993). 2 ed. São Paulo: LTr, 2011.

SENEN GONZÁLEZ, C. y DEL BONO, A. (Comp.). La revitalización sindical en Argentina: alcances y perspectivas. Buenos Aires: Prometeo, 2013.

SPALTENBERG, R. La diversidad de los conflictos laborales: dispersión y centralización en las lógicas de acción de los asalariados privados. Trabajo, Ocupación y Empleo - MTEySS. n. 11, p. 37-60, 2012.

VARELA, P. Sindicalismo de base en la Argentina de la posconvertibilidad. Hipótesis sobre sus alcances y potencialidades, In: GRIGERA, Juan. (Org.). Argentina después de la convertibilidad (2002-2011). Bueno Aires: Imago Mundi, 2013, p. 115-134.

VÁZQUEZ, M.; VOMMARO, P. La fuerza de los jóvenes: aproximaciones a la militancia kirchnerista desde La Cámpora, In: PÉREZ, Germán; NATALUCCI, Ana. (Orgs.). Vamos las bandas. Organizaciones y militancia kirchnerista. Buenos Aires: Nueva Trilce, 2012, p. 149-174.

VÉRAS DE OLIVEIRA, R. Sindicalismo e terceirização no Brasil: pontos para reflexão. Caderno CRH, n.75, v.28, p. 545-567, 2015.

ZORZOLI, L. Para pensar las prácticas sindicales. Una lectura de la sentencia por el asesinato de Mariano Ferreyra. Revista Conflictos Social, n. 11, p.32-66, 2014.

Recebido em dezembro de 2017

Aprobado em maio de 2018 